\title{
Annealing temperature effect on the properties of untreated and treated copper films with oxygen plasma
}

\author{
Alireza Hojabri • Fatemeh Hajakbari • \\ Nasrin Soltanpoor • Maryam Sadat Hedayati
}

Received: 7 May 2014/Accepted: 11 May 2014/Published online: 11 June 2014

(C) The Author(s) 2014. This article is published with open access at Springerlink.com

\begin{abstract}
In this work, the copper films were deposited on quartz substrates by DC magnetron sputtering method and then, the prepared films were annealed in air atmosphere at different annealing temperatures. Before annealing, some of the copper films, treated by oxygen plasma, for comparison of the results. The structural and morphological properties of the films have been investigated using X-ray diffraction (XRD), atomic force microscopy, and four point probe techniques. $\mathrm{XRD}$ results exhibited that the cuprous oxide phase changes to cupric oxide by enhancing of annealing temperatures. Also, oxygen plasma treatment can cause the better crystallinity for the prepared copper oxide films. The results confirm that oxygen plasma treatment, affected the crystal size, grain size, average roughness, sheet resistivity and strain of the films. The optical characteristics of the oxygen plasma treated films, such as refractive index, extinction coefficient and absorption coefficient were calculated by straight forward method proposed by Swanepoel using transmittance measurements. Moreover it was found that annealing temperature augmentation lead to decrease the optical band gap energy calculated using Tauc's relation from 2.45 to $1.80 \mathrm{eV}$.
\end{abstract}

Keywords Copper oxide $\cdot$ Oxygen plasma $\cdot$ Annealing temperature $\cdot$ Optical properties

\section{Introduction}

Copper oxide is a P-type semiconductor with a band gap in the visible or near infrared regions, non toxic nature and

A. Hojabri $(\bowtie) \cdot$ F. Hajakbari · N. Soltanpoor · M. S. Hedayati Department of Physics College of Basic Sciences, Karaj Branch, Islamic Azad University, Alborz, Iran

e-mail: hojabri@kiau.ac.ir good electrical and optical properties [1-12]. There are two crystalline forms of copper oxides, cuprous oxide or cuprite (cubic $\mathrm{Cu}_{2} \mathrm{O}$ ) and cupric oxide or tenorite (monoclinic $\mathrm{CuO}$ ). Copper oxides have many applications in diverse fields such as, solar cells [2] and photovoltaic materials [3], electrochromic devices [4], catalytic application and high$\mathrm{T}_{\mathrm{c}}$ superconductors [5].

Variety methods such as, electro deposition [6], sol-gel [7], molecular beam epitaxy [8], ultrasonic spray pyrolysis technique [9], DC reactive sputtering [10], thermal oxidation [11] and ion beam sputtering [12] have been used for the production of copper oxide films on various substrates. However, the focus of the present study is to investigate and compare the structural and morphological properties of thermal annealed $\mathrm{Cu}$ films treated and untreated with oxygen plasma. Also, for optical device applications, it is very important to study optical characteristics of copper oxide films over a wide range of wavelengths. So, the optical characteristics, including the refractive index, absorption coefficient and optical band gap of oxygen plasma treated films were determined from transmittance spectra using Swanepoel's method [13].

The structure of the paper is as follows. Following the introduction in "Introduction" we present the experimental details for the preparation, annealing and characterization of the prepared films in "Materials and methods". "Result and discussion" devoted to our results and discussions and we conclude the paper in "Conclusion".

\section{Materials and methods}

The cuprous oxide films were prepared on quartz substrates by thermal oxidation of untreated and treated copper $(\mathrm{Cu})$ films with oxygen plasma. In the first step, $\mathrm{Cu}$ thin films 
Table 1 The $\mathrm{Cu}$ films preparation conditions

\begin{tabular}{ll}
\hline Target & $\mathrm{Cu}$ \\
\hline Substrate & Quartz \\
Target-substrate distance (cm) & 6 \\
Base pressure (Torr) & $8 \times 10^{-5}$ \\
Deposition pressure (Torr) & $6 \times 10^{-2}$ \\
Voltage (V) & 200 \\
Current (mA) & 75 \\
Deposition time (min) & 2 \\
\hline
\end{tabular}

were deposited on quartz substrates using DC planar magnetron sputtering system with $\mathrm{Cu}$ target (purity of $99.999 \%$ ) under the same conditions that were shown in Table 1. Before deposition, the substrates were ultrasonically cleaned in acetone and ethanol for $15 \mathrm{~min}$ prior to loading into the deposition chamber. Thermal oxidation of $\mathrm{Cu}$ film was carried out in a quartz tube furnace at air atmosphere. For oxygen plasma treatment, some of the copper films were placed in plasma chamber of cylindrical magnetron sputtering system and exposed to the oxygen plasma at fixed conditions (without Ar gas) for $15 \mathrm{~min}$ at the pressure of $5 \times 10^{-2}$ Torr. The detail of the system can be found in ref [14]. Finally, all the prepared films were annealed in air atmosphere at different temperatures ranging from 250 to $550{ }^{\circ} \mathrm{C}$ for $240 \mathrm{~min}$ in electrical furnace.

For study of annealing temperature effect on structural and morphological properties of $\mathrm{Cu}$ films and comparison of results, the prepared films were analyzed by different methods such as X-ray diffraction (XRD; Philips PW1800), atomic force microscopy (AFM; Park Scientific Instruments Auto Probe CP) in a contact mode, Spectrophotometry (UV Ikon 922) and four-point probes.

\section{Results and discussion}

\section{$\mathrm{XRD}$ analysis}

XRD patterns of the prepared films were shown in Fig. 1a, b. It should be noted that the wide and broad peak at $22.1^{\circ}$ is related to quartz substrate. Figure 1a shows comparative patterns of XRD analysis for the untreated $\mathrm{Cu}$ films before and after annealing at different temperatures. An unannealed $\mathrm{Cu}$ film shows the diffraction peak of the (111) plane of cubic $\mathrm{Cu}$ phase (JCPDS Card no. 85-1326). This is expected, since the $\mathrm{Cu}$ has an fcc structure and the (111) facet has the lowest surface energy. The $\mathrm{Cu}$ films oxidized to the $\mathrm{Cu}_{2} \mathrm{O}$ and $\mathrm{CuO}$ after annealing at $250{ }^{\circ} \mathrm{C}$. By increasing the annealing temperature from 350 to $550{ }^{\circ} \mathrm{C}$, a single phase of $\mathrm{CuO}$ can be obtained. In addition, it can be observe that the intensity of the $\mathrm{CuO}$ peaks increases with an increase of annealing temperature up to $450{ }^{\circ} \mathrm{C}$ and, at higher temperature of $550{ }^{\circ} \mathrm{C}$ is reduced. These results are in good agreement with those reported by [15].

The XRD patterns of the $\mathrm{Cu}$ films treated by oxygen plasma and annealed at different temperatures are observed in Fig. 1b. The films formed without annealing, exhibited a broad peak corresponding to $\mathrm{Cu}_{2} \mathrm{O}$ phase with (111) direction (JCPDS Card no. 77-0199). When the film was annealed at $250{ }^{\circ} \mathrm{C}$ the (111) orientation of $\mathrm{Cu}_{2} \mathrm{O}$ peak amplified. The broadness of the peak in the as-deposited and the annealed film at $250{ }^{\circ} \mathrm{C}$ is due to small size of grains formed in these films as it can be observed in the AFM images of these films.

The film annealed at temperature of $450{ }^{\circ} \mathrm{C}$, was observed to be polycrystalline and characterized by three diffracted peaks, these diffracted peaks correspond to $\mathrm{CuO}$ of indices hkl (111), (111) and (202) (JCPDS Card no. 80-1917) that the intensity of $\mathrm{CuO}$ peaks is slightly higher than the films prepared without oxygen plasma interaction.

The average crystalline size and microstrain of the films have been obtained from the following Scherrer relations:

$D=0.9 \lambda / \beta \cos \theta$ and $\varepsilon=\beta / 4 \tan \theta$

Where, $\beta$ is the full-width at half maximum (FWHM) of the diffraction peaks in radians, $\lambda$ is the wavelength of $\mathrm{X}$-ray (1.5406 $\mathrm{nm}$ for $\operatorname{Cuk} \alpha)$ and $\theta$ is the Bragg's angle. The comparison of structural parameters (FWHM, miller indices, average crystalline size and microstrain) of untreated and oxygen plasma treated $\mathrm{Cu}$ films are shown in Table 2. According to results of Table 2, we can observe that annealing temperature augmentation lead to increase of average crystal size and decrease of microstrain. The increase in crystallite size is related to decrease in strain. Also, the increase in average crystal size after annealing might be due to decrease in grain boundaries and the amount of defect in the films. It was observed that the plasma treated films have slightly larger crystal size and smaller microstrain as compared to the untreated films. This may be due to the formation of cuprous oxide phase in the oxygen plasma treated films before annealing.

\section{Surface morphology}

The surface morphology and roughness of films were studied by atomic force microscopy (AFM). Figure $2 a-d$ shows three dimensional AFM images of untreated and treated films with oxygen plasma that were annealed at temperature of 250 and $450{ }^{\circ} \mathrm{C}$, for comparison of the results. Also, the root mean square (RMS) roughness and the average roughness values obtained from AFM measurements are shown in Table 3 . It can be seen from the Fig. 2a, b that the pyramidal types of grains were grown 

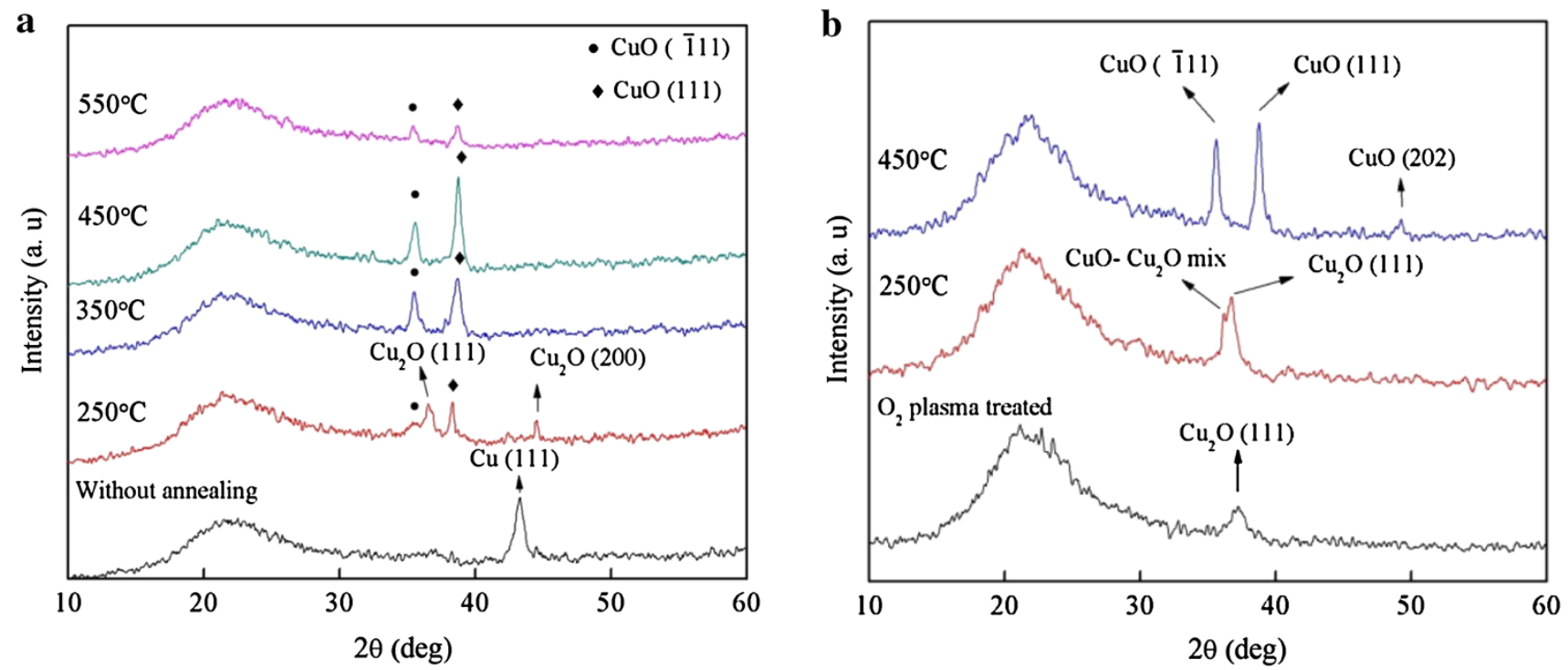

Fig. 1 a XRD patterns of untreated $\mathrm{Cu}$ films with oxygen plasma and annealed at various temperatures. $\mathbf{b}$ XRD patterns of the Cu films treated by oxygen plasma and annealed at different temperatures

Table 2 Comparison of copper oxide films structural parameters (FWHM, Miller indices, Average crystalline size and Micro strain)

\begin{tabular}{|c|c|c|c|c|c|c|c|}
\hline Conditions & $\begin{array}{l}\text { Sample number and } \\
\text { annealing temperature }\end{array}$ & $\begin{array}{l}\text { Diffraction } \\
\text { angle } 2 \theta \text { (deg.) }\end{array}$ & $\begin{array}{l}\text { Phase } \\
\text { composition }\end{array}$ & $\begin{array}{l}\text { Miller } \\
\text { indices } \\
(\mathrm{hkl})\end{array}$ & $\begin{array}{l}\text { FWHM } \\
\text { (Rad) }\end{array}$ & $\begin{array}{l}\text { Average } \\
\text { crystalline size } \\
(\mathrm{nm})\end{array}$ & Micro strain \\
\hline \multirow[t]{4}{*}{$\begin{array}{l}\text { Oxygen plasma } \\
\text { treatment }\end{array}$} & $\begin{array}{l}\text { (Sample 1) without } \\
\text { annealing }\end{array}$ & 37.26 & $\mathrm{Cu}_{2} \mathrm{O}$ & $(111)$ & $1.67 \times 10^{-2}$ & 8.75 & $3.95 \times 10^{-3}$ \\
\hline & (Sample 2) $250{ }^{\circ} \mathrm{C}$ & 36.76 & $\mathrm{Cu}_{2} \mathrm{O}$ & (111) & $1.20 \times 10^{-2}$ & 12.17 & $2.84 \times 10^{-3}$ \\
\hline & (Sample 3) $450{ }^{\circ} \mathrm{C}$ & 35.64 & $\mathrm{CuO}$ & $(\overline{1} 11)$ & $8.37 \times 10^{-3}$ & 17.39 & $1.99 \times 10^{-3}$ \\
\hline & (Sample 3) $450{ }^{\circ} \mathrm{C}$ & 38.76 & $\mathrm{CuO}$ & (111) & $6.97 \times 10^{-3}$ & 21.05 & $1.64 \times 10^{-3}$ \\
\hline \multirow[t]{4}{*}{$\begin{array}{l}\text { Without oxygen } \\
\text { plasma treatment }\end{array}$} & $\begin{array}{l}\text { (Sample 4) without } \\
\text { annealing }\end{array}$ & 43.25 & $\mathrm{Cu}$ & (111) & $1.30 \times 10^{-2}$ & 11.46 & $3.02 \times 10^{-3}$ \\
\hline & (Sample 5) $250^{\circ} \mathrm{C}$ & 36.56 & $\mathrm{Cu}_{2} \mathrm{O}$ & (111) & $1.30 \times 10^{-2}$ & 11.23 & $3.05 \times 10^{-3}$ \\
\hline & (Sample 6) $450^{\circ} \mathrm{C}$ & 35.56 & $\mathrm{CuO}$ & $(\overline{1} 11)$ & $1.01 \times 10^{-2}$ & 14.41 & $2.04 \times 10^{-3}$ \\
\hline & (Sample 6) $450{ }^{\circ} \mathrm{C}$ & 38.76 & $\mathrm{CuO}$ & (111) & $7.50 \times 10^{-3}$ & 19.59 & $1.76 \times 10^{-3}$ \\
\hline
\end{tabular}

perpendicular to the substrate surface for the films formed without oxygen plasma. The surface roughness of films increased by enhancing of annealing temperature may be due to the phase change and the formation of larger grains due to the diffusion effect. In addition, it can observe that the films treated by oxygen plasma are rougher than the untreated films. The increase of roughness in this case can be attributed to the interaction of reactive particles from plasma with the surface and surface oxidation that can be seen in XRD results (Fig. 1b).

\section{Electrical properties}

The sheet resistance of films was measured using a four point probe, several measurements were taken from each sample and average is reported with a deviation of $<10 \%$ in Table 3 . The results showed that by increasing of annealing temperature the sheet resistivity of films decreased may be due to the phase transition from $\mathrm{Cu}_{2} \mathrm{O}$ to $\mathrm{CuO}$ and increase of films crystallinity that have been shown in XRD results. Also, the sheet resistivity of oxygen plasma treated films is larger than the untreated films.

Optical characteristics

For optical investigation, the films treated with oxygen plasma were chosen. Because interference fringes due to the high quality and good structure properties of these films can be observed in optical transmittance spectra and we can employ the Swanepoel's method to determine the optical constant such as refractive index (n) and extinction 

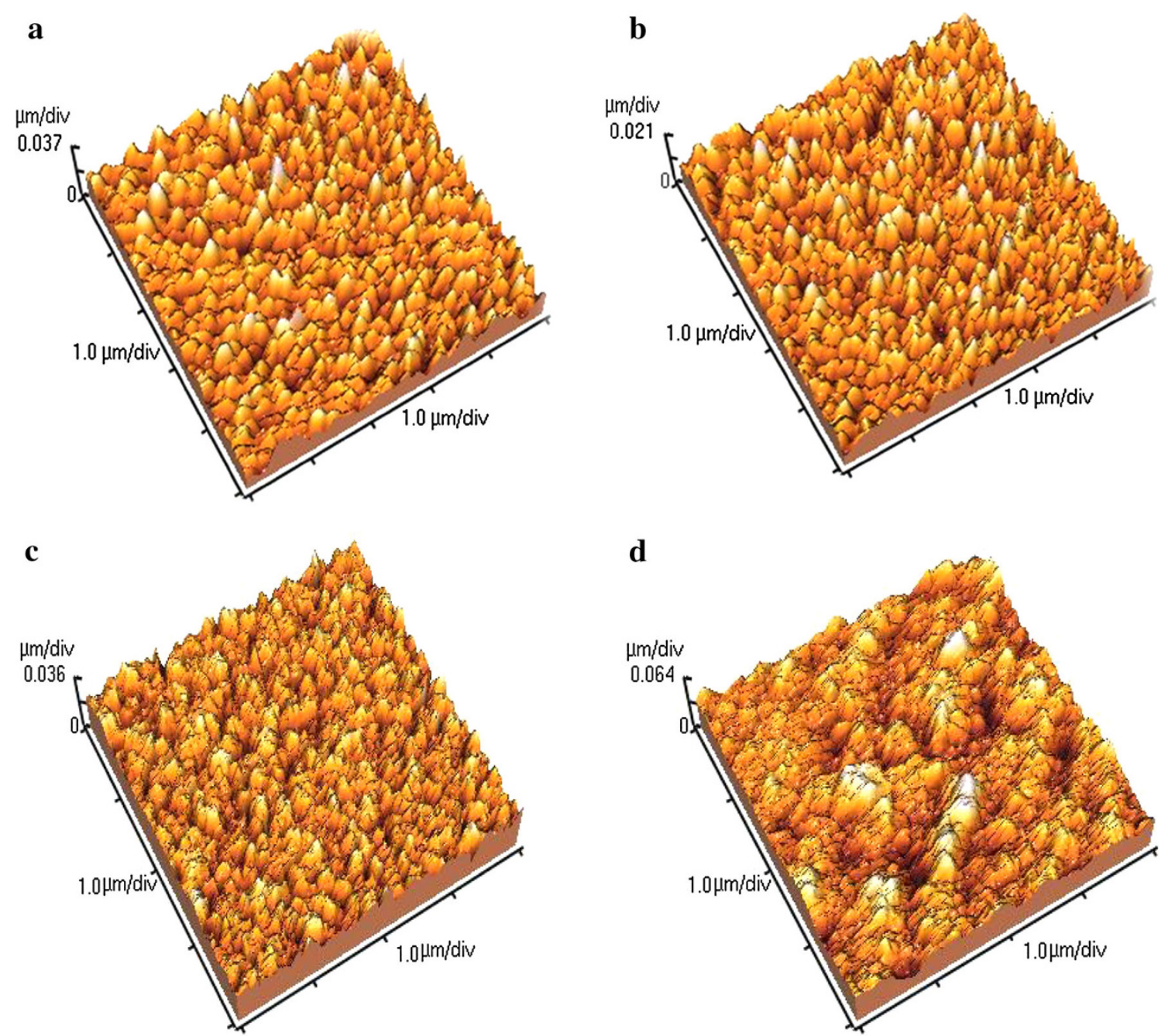

Fig. $23 \mathrm{D}$ AFM images of untreated copper films with oxygen plasma and annealed at: a $250{ }^{\circ} \mathrm{C}, \mathbf{b} 450{ }^{\circ} \mathrm{C}$ and oxygen plasma treated films and annealed at: c $250{ }^{\circ} \mathrm{C}, \mathbf{d} 450{ }^{\circ} \mathrm{C}$

Table 3 The roughness and sheet resistivity of untreated and treated cu films with oxygen plasma and annealed at 250 and $450{ }^{\circ} \mathrm{C}$

\begin{tabular}{lllll}
\hline Sample & $\begin{array}{l}\text { Annealing } \\
\text { temperature } \\
\left({ }^{\circ} \mathrm{C}\right)\end{array}$ & $\begin{array}{l}\text { RMS } \\
\text { roughness } \\
(\mathrm{nm})\end{array}$ & $\begin{array}{l}\text { Average } \\
\text { roughness } \\
(\mathrm{nm})\end{array}$ & $\begin{array}{l}\text { Sheet } \\
\text { resistivity } \\
(\Omega / \square)\end{array}$ \\
\hline $\begin{array}{l}\text { Untreated } \\
\text { films with } \\
\text { oxygen } \\
\text { plasma }\end{array}$ & 250 & 5.36 & 4.25 & $8.96 \times 10^{3}$ \\
$\begin{array}{l}\text { Treated films } \\
\text { with }\end{array}$ & 250 & 10.65 & 8.49 & $4.83 \times 10^{2}$ \\
$\begin{array}{l}\text { oxygen } \\
\text { plasma }\end{array}$ & 450 & 7.36 & 5.64 & $2.50 \times 10^{4}$ \\
\hline
\end{tabular}

coefficient $(k)$. The normal incidence optical transmittance spectra of the films and quartz substrate in the wavelength range of 400-1,500 $\mathrm{nm}$ are shown in Fig. 3.

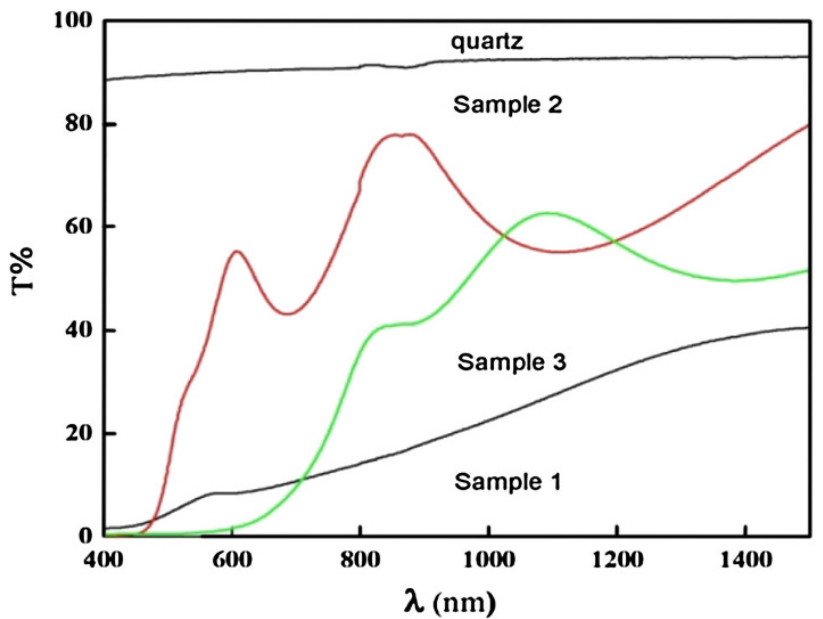

Fig. 3 Transmittance spectra of treated copper films with oxygen plasma, and annealed at different temperatures 
We can observe that the curve of the unannealed $\mathrm{Cu}_{2} \mathrm{O}$ film is smooth, whereas the curves corresponding to annealed films exhibit interference fringes. The annealed $\mathrm{Cu}_{2} \mathrm{O}$ films are transparent in the visible region and exhibit sharp absorption edges that can be attributed to the good crystallinity and low defect concentration in the film. Whereas an unannealed film doesn't shows sharp absorption edge due to the low crystallinity level and high defect density near the band edge. Also by annealing, the film's transparency is increased and the optical properties of films improved due to the increase of crystallinity and decrease the defect density at the edge of energy band gap. The transmittance of the annealed film at $450{ }^{\circ} \mathrm{C}$ is lower than the annealed film's at $250{ }^{\circ} \mathrm{C}$. These results are due to the transformation of $\mathrm{Cu}_{2} \mathrm{O}$ to $\mathrm{CuO}$ as it was evidenced by the XRD results.

The annealed films refractive index computed using the Swanepoel's method, are shown in Fig. 4. The refractive index was modeled by the two-term Cauchy dispersion relations [16]. The Cauchy dispersion relations for two annealed samples 2 and 3 are:

$$
\begin{aligned}
n_{\text {sample } 2} & =2.30+\frac{2.19 \times 10^{5}}{\lambda^{2}}, n_{\text {sample3 }} \\
& =2.15+\frac{8.6 \times 10^{4}}{\lambda^{2}} .
\end{aligned}
$$

Figure 4 shows the dispersion curves of the calculated refractive index, $n$, along with the experimental values. It is
Fig. 4 Variation in refractive index $(n)$ versus wavelength $(\lambda)$ for samples 2 and 3
Fig. 5 Dependence of extinction coefficient $(k)$ on wavelength $(\lambda)$ for samples 2 and 3
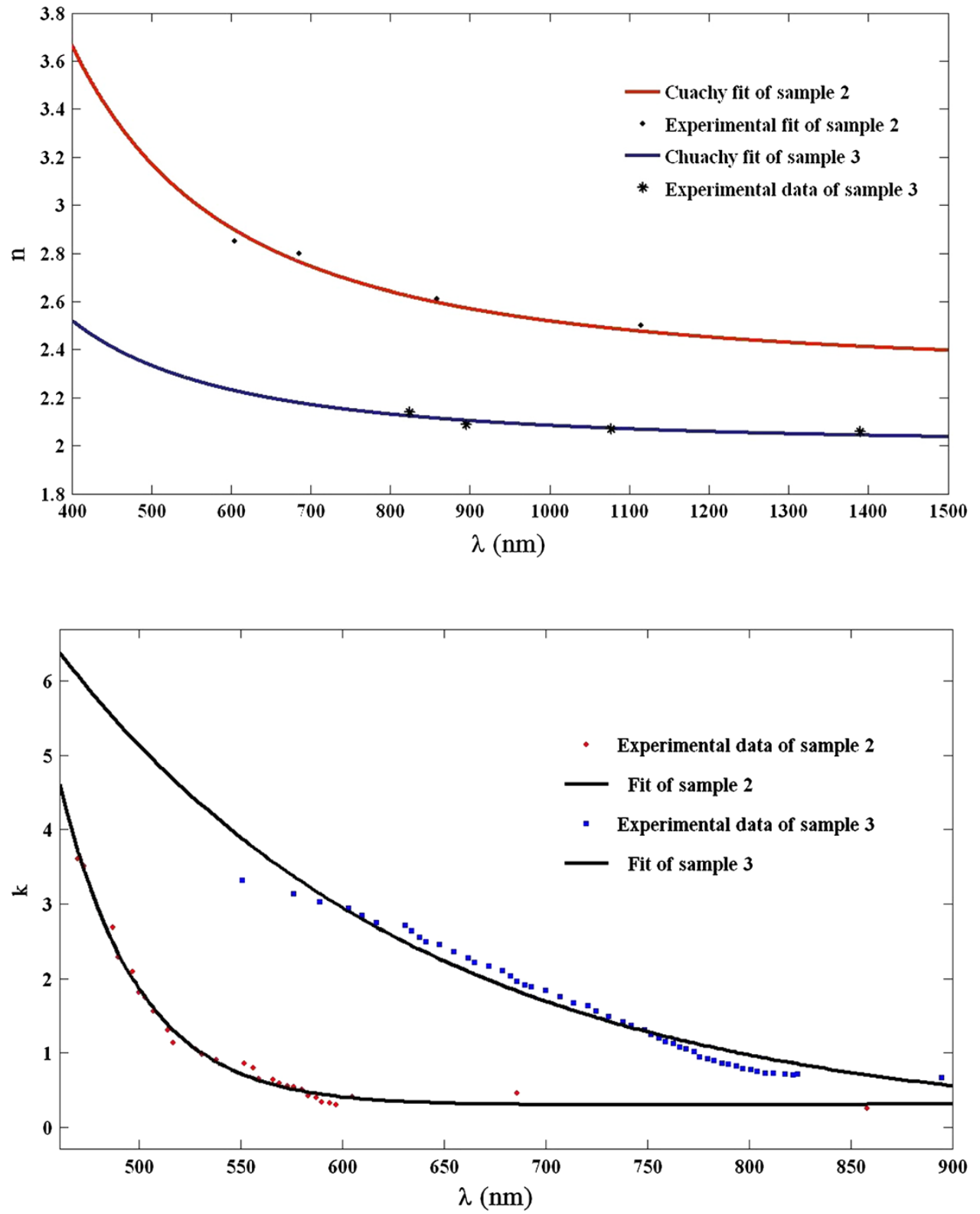
Fig. 6 Dependence of absorption coefficient $(\alpha)$ on wavelength $(\lambda)$ for samples 2 and 3

Fig. 7 Plot of $(\alpha h v)^{2}$ versus photon energy $(h v)$ for annealed $\mathrm{Cu}_{2} \mathrm{O}$ films
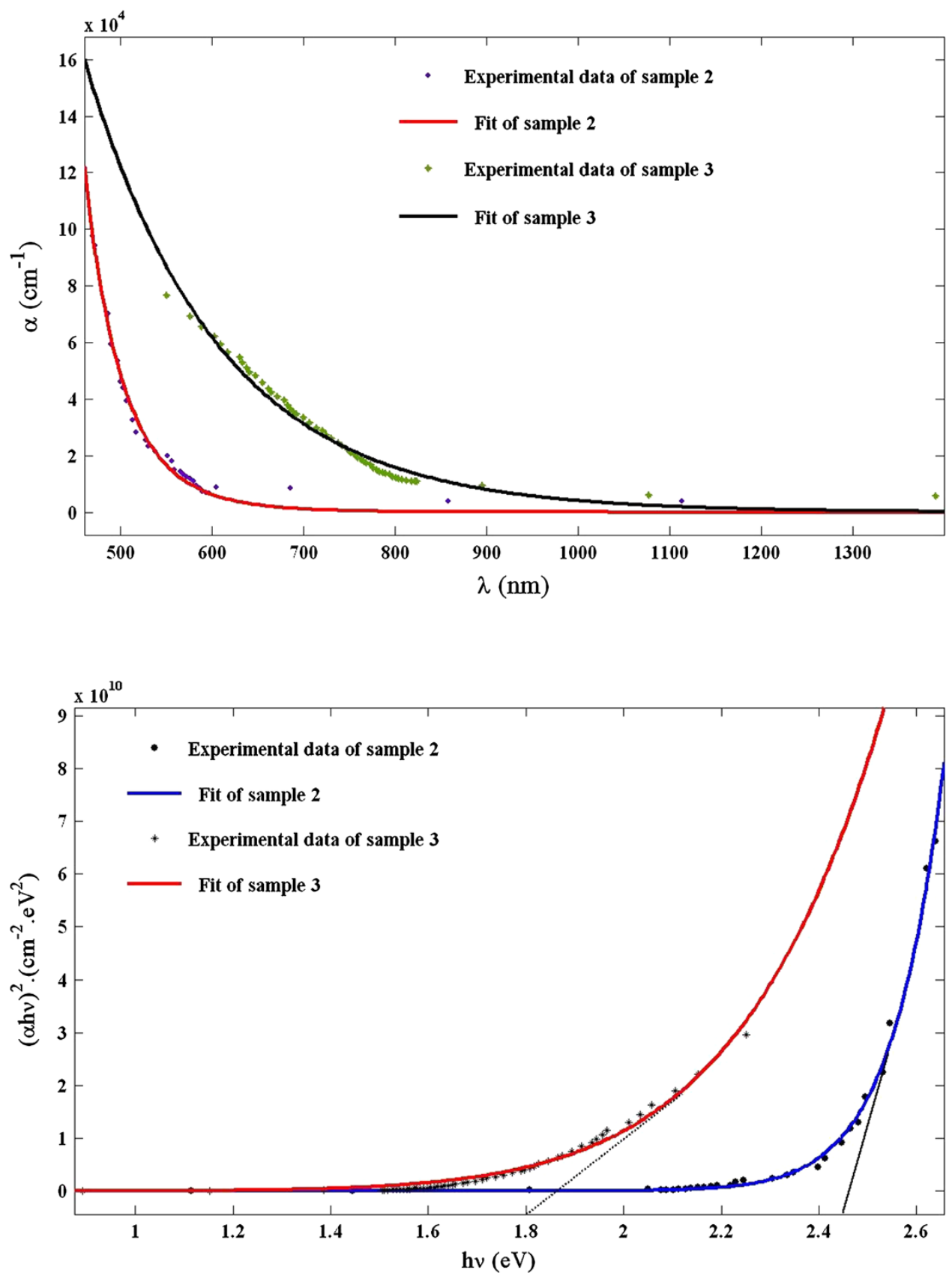

clear that both the experimental and calculated values of refractive index using the Cauchy dispersion are extensions to each other. Also, it is observed that the refractive index, $n$, decreased with increasing wavelength and tends to be constant at longer wavelength. The values of the refractive index in this study decreased from 2.91 to 2.39 and 2.23 to 2.04 for samples 2 and 3 respectively, with increase of wavelength from 600 to $1,500 \mathrm{~nm}$. The $\mathrm{n}$ values of the copper oxide films calculated in the present study are in good agreement with those reported by $[1,17,18]$ for crystalline films. Moreover, $n$ of sample 3 (that was annealed at $450{ }^{\circ} \mathrm{C}$ ) is lower than of sample 2 over the entire measured wavelength range. This reduction of refractive index can be attributed to phase transition from $\mathrm{Cu}_{2} \mathrm{O}$ to the $\mathrm{CuO}$.

The extinction coefficient, $k$, is determined by $k=\frac{\alpha \lambda}{4 \pi}$, and the wavelength dependence of $k$, is shown in Fig. 5. It is clearly observed that the extinction coefficient decreases with increasing wavelength. The wavelength dependence of the absorption coefficient for the annealed films is given in Fig. 6. It can be seen that the annealed films show a very weak absorption coefficient at the range of $800-1,500 \mathrm{~nm}$ but for the photon energies in the visible region and near-IR spectral range, the films have relatively high absorption coefficient of $10^{4} \mathrm{~cm}^{-1}$. Such a high absorption coefficient 
implies that these films are very suitable for solar energy applications. Using the derived absorption coefficient $\alpha$, the optical band gap of the films was estimated by extrapolating the linear portion of the plot of $(\alpha h v)^{2}$ versus $(h v)$ to $(\alpha h v)=0$ according to Tauc's relation [19]. Figure 7 shows the plot of $(\alpha h v)^{2}$ versus $(h v)$ for two annealed samples.

The plots indicate a direct optical band gap for both annealed films which is a desired property for photovoltaic application. We can observed that the value of optical band gap of the annealed film at $250{ }^{\circ} \mathrm{C}$ is $2.45 \mathrm{eV}$ but for $450{ }^{\circ} \mathrm{C}$ annealed film, when the diffraction peaks of $\mathrm{CuO}$ are detected in the $\mathrm{X}$-ray pattern, the optical band gap decreases close to $1.80 \mathrm{eV}$. The values of optical band gap estimated in this study are in good agreement with the values reported by [20-23] for copper oxide films.

\section{Conclusions}

Influence of annealing temperature on structural and morphological properties of untreated and treated $\mathrm{Cu}$ films with oxygen plasma were investigated. The results show that the films prepared with oxygen plasma treatment have a larger crystal size, average roughness, sheet resistivity and smaller strain comparison to the untreated films. Also, all the films crystallinity is improved by annealing temperature up to $450{ }^{\circ} \mathrm{C}$. Optical characteristics of the films treated by oxygen plasma were studied by Swanepoel's method. The refractive index decreased when the annealing temperature enhanced from 250 to $450{ }^{\circ} \mathrm{C}$ and the direct allowed band gap values were changed from 2.45 to $1.80 \mathrm{eV}$, due to the conversion of $\mathrm{Cu}_{2} \mathrm{O}$ to $\mathrm{CuO}$ phase.

Acknowledgments This work was supported by Department of Physics, College of Basic Sciences, Karaj Branch, Islamic Azad University, Alborz, Iran.

Open Access This article is distributed under the terms of the Creative Commons Attribution License which permits any use, distribution, and reproduction in any medium, provided the original author(s) and the source are credited.

\section{References}

1. Reddy, A.S., Rao, G.V., Uthanna, S., Reddy, P.S.: Structural and optical studies on de reactive magnetron sputtered $\mathrm{Cu}_{2} \mathrm{O}$ films. Mater. Lett. 60, 1617 (2006)

2. Rafea, M.A., Roushdy, N.: Determination of the optical band gap for amorphous and nanocrystalline copper oxide thin films prepared by SILAR technique. J. Phys. D Appl. Phys. 42, 015413 (2009)

3. Samarasekara, P., Kumara, N.T.R.N., Yapa, N.U.S.: Sputtered copper oxide $(\mathrm{CuO})$ thin films for gas sensor devices. J. Phys. Condens. Mater. 18, 2417 (2006)
4. Richardson, T.J., Slack, J.L., Rubin, M.D.: Electrochromism in copper oxide thin films. Electrochim. Acta 46, 90 (2001)

5. Pei, T.H., Huang, Y.T.: Temperature modulation of the superprism effect in photonic crystals composed of the copper oxide high-temperature superconductor. Jpn. J. Appl. Phys. 46, L593 (2007)

6. Mahalingam, T., Chitra, J.S.P., Chu, J.P., et al.: Structural and annealing studies of potentiostatically deposited $\mathrm{Cu}_{2} \mathrm{O}$ thin films. Sol. Energy Mater. Sol. Cells 88, 209 (2005)

7. Ray, S.C.: Preparation of copper oxide thin film by the sol-gellike dip technique and study of their structural and optical properties. Sol. Energy Mater. Sol. Cells 68, 307 (2001)

8. Yubinetsky, I.L., Thevulhasan, S., Mc Cready, D.E., Baer, D.R.: Formation of single-phase oxide nanoclusters: $\mathrm{Cu}_{2} \mathrm{O}$ on SrTiO3(100). J. Appl. Phys. 94, 7926 (2003)

9. Kose, S., Akay, F., Biligin, V., Akyuz, I.: Some physical properties of copper oxide films: The effect of substrate temperature. Mater. Chem. Phys. 111, 351 (2008)

10. Rastkar, A.R., Niknam, A.R., Shokri, B.: Characterization of copper oxide Nanolayer deposited by direct current magnetron sputtering. Thin Solid Films 517, 5464 (2009)

11. Khojier, K., Savaloni, H., Sadeghi, Z.: A comparative investigation on growth, nanostructure and electrical properties of copper oxide thin films as a function of annealing conditions. J. Theor. Appl. Phys 8, 116 (2014)

12. Yoon, K.H., Choi, W.J., Kang, D.H.: Photoelectrochemical properties of copper oxid thin films coated on an n-Si substrate. Thin Solid Films 372, 250 (2003)

13. Dorranian, D., Dejam, L., Mosayebian, G.: Optical characterization of $\mathrm{Cu}_{3} \mathrm{~N}$ thin film with Swanepoel method. J. Theor. Appl. Phys. 6, 13 (2012)

14. Hojabri, A., Haghighian, N., Yasserian, K., Ghoranneviss, M.: The effect of nitrogen plasma on copper thin film deposited by DC magnetron sputtering. IOP Conf. Ser. (Mater. Sci. Eng.) 12, 012004 (2010)

15. Figueiredo, V., Elangovan, E., Goncalves, G., et al.: Effect of post-annealing on the properties of copper oxide thin films obtained from the oxidation of evaporated metallic copper. Appl. Surf. Sci. 254, 3949 (2008)

16. Jenkins, F.A., White, H.E.: Fundamentals of optics. McGrawHill, New York (1981)

17. Balamurugan, B., Mehta, B.R.: Optical and structural properties of nanocrystalline copper oxide thin films prepared by activated reactive evaporation. Thin Solid Films 396, 90 (2001)

18. Papadimitropoulos, G., Vourdas, N., Vamvakas, V.E., Davazoglou, D.: Optical and structural properties of copper oxide thin films grown by oxidation of metal layers. Thin Solid Films $\mathbf{5 1 5}$, 2428 (2006)

19. Tauc, J., Menth, A.: States in the gap. J. Non Cryst. Solids 8, 569 (1972)

20. Alkoy, E.M., Kelly, P.J.: The structure and properties of copper oxide and copper aluminium oxide coatings prepared by pulsed magnetron sputtering of powder targets. Vacuum 79, 221 (2005)

21. Ooi, Ch., Goh, G.K.L.: Formation of cuprous oxide films via oxygen plasma. Thin Solid Films 518, e98 (2010)

22. Akkari, F.C., Kanzari, M., Rezig, B.: Preparation and characterization of obliquely deposited copper oxide thin films. Eur. Phys. J. Appl. Phys. 40, 49 (2007)

23. Ogwu, A.A., Bouquerel, E., Ademosu, O., et al.: The influence of rf power and oxygen flow rate during deposition on the optical transmittance of copper oxide thin films prepared by reactive magnetron sputtering. J. Phys. D Appl. Phys. 38, 266 (2005) 